\title{
Hospital San Juan de Dios de Arequipa: trescientos sesenta años de una historia fantasmal
}

\section{San Juan de Dios Hospital in Arequipa: three hundred and sixty years of a ghostly story}

Álvarez-Carrasco R. Hospital San Juan de Dios de Arequipa: trescientos sesenta años de una historia fantasmal. Rev Soc Peru Med Interna. 2020;33(3): I 19-124.

https://doi.org/10.36393/spmi.v33i3.551

\begin{abstract}
RESUMEN
El objeto de este artículo es reconstruir la existencia del hospital San Juan de Dios de Arequipa, que, a pesar de sus trescientos sesenta años de existencia al servicio de una de las ciudades más importantes del Perú, ha sido completamente olvidado por sus coterráneos y gran parte de los historiadores de la medicina peruana. Esta investigación permite igualmente apreciar la evolución administrativa, normativa y científica de un nosocomio colonial y, finalmente, experimentar en primera línea sus cuatro décadas finales, probablemente de las más tortuosas de su larga existencia en que se sobrevivió a sí mismo y que concluyeron de un modo insólito, nunca visto antes y después en los anales hospitalarios del país.
\end{abstract}

Palabras claves: medicina peruana, hospital, salud, época colonial, historia.

\section{ABSTRACT}

The purpose of this article is to reconstruct the existence of the San Juan de Dios hospital in Arequipa, which, despite its three hundred and sixty years of existence serving one of the most important cities in Peru, has been completely forgotten by its compatriots and a large part of the historians of the Peruvian medicine. This research also allows us to appreciate the administrative, normative and scientific evolution of a colonial hospital and, finally, to experience, on the front line, its final four decades, probably the most tortuous of its long existence, in which it survived by itself and concluded in an unusual way, never seen before and after in the hospital records of the country.

Keywords: Peruvian medicine, hospital, health, Colonial times, history.

\section{INTRODUCCIÓN}

En el virreinato del Perú, la Corona propició el establecimiento de instituciones relacionadas con la sanidad, como hospitales, universidades y protomedicato, que también tenían un objetivo político, contribuyendo a

Médico patólogo clínico. Instituto Nacional Materno Perinatal, Lima. Asociación de Historia de la Medicina Peruana y Parques Conmemorativos, Lima, Perú. consolidar el control sobre los territorios conquistados. ${ }^{1}$ Los hospitales se regían por las disposiciones monárquicas que, entre otros fines, buscaban evitar la propagación de las enfermedades, concibiéndolos como espacios de curación de los enfermos, bajo la premisa de la caridad cristiana, pero las capacidades de la medicina y las deplorables condiciones de muchos de ellos, los convirtieron en lugares para el bien morir de los pobres de solemnidad. ${ }^{2}$

\section{Primera administración del cabildo 1552-1648}

Arequipa se fundó el 15 de agosto de 1540, teniendo como génesis la plaza mayor y las calles circundantes que comprendían cuarenta y nueve manzanas por lado y en cuadro, y en una de ellas se fundaría el hospital San Juan de Dios que por más de tres siglos fue su principal establecimiento sanitario.

En el siglo XVI se produjeron sus dos fundaciones, la primera el sábado 27 de setiembre de 1552, cuando Hernando de Mena, a nombre del cabildo de Lima se presentó ante su par de Arequipa mostrando las instrucciones de Carlos I, y que reclamaba el producto de los relaves de las minas para erigir hospitales en el reino. Los miembros de esta última corporación decidieron fundar uno en su ciudad, como consta en el acta que firmaron ante el escribano Gaspar Hernández. ${ }^{3}$ 
Se adquirieron las casas del español Juan de San Juan, se le designó un médico, el licenciado Marco Antonio, en el 14 de febrero de 1553; un mayordomo, Noguerol de Ulloa, el 7 de julio de 1553; y, se tomó posesión del predio, en agosto de 1553, pero la falta de rentas permanentes y suficientes lo hizo languidecer por cinco años, en que operó desorganizada y discontinuamente. ${ }^{3,4}$

El martes 30 de setiembre de 1558, el hospital se fundó por segunda vez, cuando el cabildo autorizó hacerlo al licenciado Alonso Martínez de Rivera, gracias a los generosos aportes de Catalina de Mazuelo y Castro. En 1559, el virrey Andrés Hurtado de Mendoza aprobó su fundación y le asignó un noveno y medio de los diezmos. ${ }^{5}$ El 5 de octubre de 1556, el cabildo nombró como médico al licenciado Diego Núñez y en 1561 recibió como epónimo a Nuestra Señora de los Remedios, bajo la advocación de Nuestra Señora de la O. ${ }^{3,6}$ En la Colonia era frecuente que las autoridades locales contravinieran o interpretaran las disposiciones provenientes de España y Lima. Por ello, el virrey Pedro Álvarez de Toledo (1639-1648) comisionó a Francisco de Arriaga y Soto, juez mayor visitador y cobrador de sus rentas, para formar un libro de las rentas y censos del hospital, guardando sus archivos y papeles en una caja ubicada en el cabildo, que tendría dos llaves, una en manos del mayordomo del nosocomio y la otra en poder del secretario del juez visitador. ${ }^{6}$

\section{Administración de la orden hospitalaria de San Juan de Dios, 1648-1826}

El 15 de mayo de 1600, Felipe III ordenó que los hermanos de San Juan de Dios se encargasen de los hospitales en las Indias, quienes arribaron a Arequipa en $1619 .{ }^{7}$ Pero, recién el 2 de enero de 1648, Andrés Díaz Manso, en representación de la orden, aceptó del cabildo las capitulaciones y el hospital, gracias a que el 8 de mayo de 1640, Felipe IV ordenó que el cabildo entregara el tomín que los indios pagaban "para su hospitalidad".

Algunos obispos de Arequipa hicieron mejoras en su infraestructura; alcanzando su mayor extensión con siete salas, cuatro para hombres con 42 camas y tres para mujeres con 50 camas, ocupando la segunda manzana de la calle San Juan de Dios, llegando hasta el cruce con la calle Deán Valdivia, a doscientos metros de la plaza de armas. ${ }^{9-11}$ Sin embargo, los numerosos movimientos sísmicos produjeron daños en aquella infraestructura.

En 1793, Juan de Ríos Rodríguez era su prior; ${ }^{12}$ en 1795, Pedro Ustari; ${ }^{13}$ en 1796, Pedro Gotardi; ${ }^{14}$ y, en 1797 , Francisco Corrales. ${ }^{15}$ Por entonces, contaba con veinticinco religiosos y una renta anual de 9559 pesos. ${ }^{15}$

En España, los liberales restablecían la constitución de 1812 y aprobaron la ley del 25 de octubre de 1820 que ordenaba que no habría más de un convento de una misma orden en cada pueblo y cuando no alcanzaran a 24 religiosos se reunirían en el convento más inmediato de la misma orden, que se hizo obligatoria desde mayo de 1822 cuando la administración del hospital se transfirió al cabildo. ${ }^{16} \mathrm{Y}$, como se desatendió a los militares que solían utilizar dicho hospital, los mandos castrenses exigieron 3000 pesos para instalar un nosocomio militar. ${ }^{17}$

El 30 de agosto de 1823, llegó a la ciudad el general Antonio José de Sucre, cuyas tropas fueron el origen de una epidemia de disentería, con gran mortandad entre los pacientes del hospital. ${ }^{18} \mathrm{La}$ independencia posibilitó el fugaz regreso de la orden de San Juan de Dios, y en 1825 resurgió el brote de disentería, que el doctor Juan Manuel Vargas, teniente del protomedicato en Arequipa, trató con calomelanos. ${ }^{18} \mathrm{El}$ gobierno dictó el decreto del 26 de setiembre de 1826 que secularizó las órdenes religiosas, subrogando del hospital a la orden de San Juan de Dios, que volvió al cabildo.

\section{Segunda administración del cabildo, 1826-1848}

En aquellos años, el cabildo le asignó un presupuesto exiguo; y, durante la Confederación Perú Boliviana (18361839), el general Ramón Herrera, presidente del estado Sud Peruano, decretó, el 6 de mayo de 1837, el reglamento del protomedicato de aquel estado, cuya sede residiría en Arequipa. Luego se nombró protomédico al doctor Agustín Torrally, y el 19 de mayo de 1838 se reglamentó la asistencia hospitalaria, disponiendo que los nosocomios estarían a sotavento y distantes de las ciudades, ${ }^{19}$ por lo que su cumplimiento hubiera significado la desaparición del hospital San Juan de Dios. Pero, en enero de 1839, la confederación fue derrotada militarmente y se extinguió. En 1847, ante su mala condición, el gobierno ordenó al prefecto de Arequipa tomar de la tesorería 2747 pesos para completar el presupuesto de refacción del hospital y los baños de Yura. ${ }^{20}$

\section{Administración de la Sociedad de Beneficencia de Arequipa, 1848-1912}

Desde la década de 1830, se modificó el sistema de administración de los hospitales del país que, paulatinamente, pasaron a las sociedades de beneficencia. La de Arequipa (SBA) se creó por decreto del 28 de octubre de 1848 , siendo su jefe nato el prefecto, quien podía designar al director.

El 1 de diciembre se instaló la SBA, el general Pedro Nolasco Cisneros de la Torre, prefecto de Arequipa, designó a Juan Mariano Goyeneche y Barreda como su primer presidente y a Luís Gamio como mayordomo del hospital.

En la década de 1850, Mateo Paz Soldán, afamado abogado y polígrafo arequipeño, criticó su localización, señaló que todos sus pacientes eran pobres, su mal estado se explicaba por lo exiguo de las rentas y se preguntaba “¿Cómo ha habido más de 300000 pesos para hacer una deslumbrante catedral y no hay 100000 para la obra más humanitaria e interesante a la salud general de los moradores de esta ciudad?". 21

El 21 de setiembre de 1867, el presidente Mariano Ignacio Prado decretó la contratación de diez hermanas de San Vicente de Paul para servir en el "Hospital y Casa de Huérfanos de la ciudad de Arequipa”, y desde su llegada, la superiora tomó la administración económica. ${ }^{6}$

El 24 de abril de 1868, la SBA aprobó el reglamento 
provisional del hospital, que redactaron los socios Hermógenes Cornejo y Mariano Vargas (Figura 1), en el que se determinó que el mayordomo era la máxima autoridad; y, sería visitado por un diputado que le notificaría cualquier defecto que evidenciara e incluso podía comunicarlo directamente al director de la $\mathrm{SBA}^{22}$ El médico y el cirujano, jefes inmediatos de las enfermerías, realizarían dos visitas diarias, a las seis o siete de la mañana y al mediodía o en la tarde; y, en caso de ausencia mayor de un día, nombrarían por cuenta propia a su reemplazante. Los enfermeros serían dos, uno para hombres y otro para mujeres, siendo los jefes de las enfermerías después de los facultativos. ${ }^{22}$

El 13 de agosto de 1868, Arequipa fue asolada por un terrible terremoto. El presidente José Balta y Montero se había instalado en el poder apenas el 2 de agosto, once días antes de la tragedia, y una catástrofe tan lejana a la centralista Lima hubiera pasado inadvertida pero el 19 de agosto llegaron las terribles noticias, lo que da una idea de la incomunicación en que vivía el territorio del Perú. Balta envió una comisión encabezada por Luciano Benjamín Cisneros, ministro de Justicia, Instrucción, Culto y Beneficencia, quien permaneció en Arequipa por quince días. $^{23}$

El 1 de setiembre, Cisneros informaba sobre los daños en el hospital, el nombramiento de una comisión para emplazar uno provisional y la instalación de la Junta Central de Auxilios, el 6 de setiembre, que adquirió por 6694 soles un terreno en el lugar llamado La Palma para construir el nuevo nosocomio, el cual fue bendecido por Pedro José Tordoya, obispo de Tiberiópolis, el domingo 13 de setiembre. ${ }^{23}$

\title{
REGLAMENTO PROVISIONAL
}

DEL

\section{HOSPITAL}

$\mathrm{DE}$

\section{SAN JUAN DE DIDS}

DE

\section{ARFQUIPA.}

\begin{abstract}
MANDADO ORSERVAR POR LA JUNTA PERMANENTE DE BENEFICENCIA EN SESION DE 24 DE ABRIL DE 1868 , SIENDO DIRECTOR EL S. D. D. EVARISTO VARGAS.
\end{abstract}

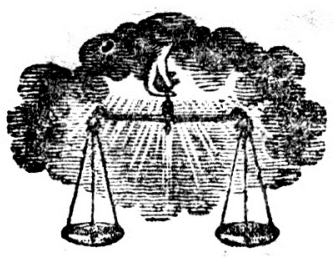

Imprenta dr Frakcisco Toakez. Calle del "Cavel," N. 56.

1868.

Figura I. Reglamento provisional del hospital San Juan de Dios de Arequipa. Imprenta de Francisco Ibáñez, Arequipa, 1868. 
El 1 de octubre, Balta decretó la construcción del nuevo hospital y el 13 de octubre, el coronel Pedro Balta y Montero, hermano del presidente era designado prefecto del departamento de Arequipa. ${ }^{23}$

El tortuoso y fallido proceso de tal construcción está detallado en el legajo del remate público del nuevo hospital de Arequipa, Prefectura Departamental de Arequipa 1869-1870, el cual se inició cuando la Junta de Almoneda del departamento encargada de los remates y subastas públicos, y presidida por Pedro Balta, designó una comisión para elaborar las bases de la obra del nosocomio que se encargaron a Teófilo M. Fioretti, ingeniero del Estado, que tomó como referencia al hospital de Lariboisiere de París, siendo aprobadas por esta comisión con ciertas modificaciones, el 26 de noviembre de 1869. Tres días después, la Junta de Almoneda aceptó la propuesta que había aprobado dicha comisión.

La subasta se llevó a cabo el 18 de enero de 1870, declarándose ganador a Raymundo León Prado que aceptó construirlo por los 248011 soles presupuestados por Fioretti pero, Lucas Poblete, arquitecto del Estado, hizo serias observaciones a las bases que obligaron a derivar el expediente al fiscal García que recomendó comprobar tales inconformidades y luego convocar a la Junta de Almoneda para decidir el asunto, puntualizando lo extemporáneo de las observaciones de Poblete. Balta nombró a Isidoro Cárdenas y José Antonio de Vivanco Corrales para hacer las comprobaciones pertinentes, quienes, en efecto, concluyeron que las bases tenían serios defectos y el terreno adquirido no era adecuado.

El 11 de marzo la Junta de Almoneda declaró nulo el remate y Balta designó a Fioretti y Poblete, para levantar el nuevo plano y presupuesto, a pesar que ambos estuvieron involucrados en la discrepancia pero, por entonces, eran muy escasos los ingenieros y arquitectos competentes. Fioretti, que era uno de los doce ingenieros de Estado que había en el Perú, preparó los planos y el presupuesto que ascendió a 291047 soles. ${ }^{24}$ Poblete señaló siete observaciones a tales documentos, entre ellas el grosor de las murallas, el material de las cornisas y pilastras y la extensión de los cimientos. Balta debió convocar a Mateo Garzón como perito dirimente, quien dio la razón a Poblete, respecto al grosor de las murallas y el material de las cornisas y pilastras, y a Fioretti en la extensión de los cimientos; ello definió la infraestructura del futuro hospital.

El 30 de abril se reunió la Junta de Almoneda y designó una comisión para verificar si el terreno adquirido era adecuado, la cual integraron Mateo Garzón, Juan Corrales Melgar, José Casimiro Valdés, José Antonio Vivanco y Lucas Poblete, quienes señalaron que el terreno comprado era inaparente y el más conveniente era uno "situado entre la prolongación y al término de las calles de San Juan de Dios y San Camilo, a espalda de la calle nueva, que baja recta de la ranchería al callejón de la Palma, en los terrenos de los señores Campos y Goyeneche", a sotavento, elevado respecto a la población, con agua suficiente y un desnivel hacia la acequia de San Juan de Dios, estaba abierto en todas las direcciones y era plano y ,curiosamente, solo distaba 134 metros del terreno considerado inadecuado.

Este informe fue objetado por la Junta de Almoneda, el 13 de mayo, que aprobó la construcción del hospital en el terreno previamente adquirido con la única modificación, propuesta por el deán Juan Gualberto Valdivia, que variaba su dirección espacial; es decir, la fachada principal que debía dar frente a la calle de Santa Marta, se cambiaría al costado de San Camilo, "siendo su dirección longitudinal de oriente a occidente, principiando de la esquina de la nueva calle que se abre prolongando la calle que viene de Santa Marta a la Palma”.

El 7 de julio de 1870, el prefecto Balta comunicó al ministro de Gobierno, Policía y Obras Públicas que el 17 de aquel mes se realizaría la nueva subasta y, el 2 de octubre, le informó que la refacción del hospital San Juan de Dios estaba terminada y las obras del nuevo, denominado Balta, en homenaje al presidente de la República, se habían iniciado, luego de inscribirse la escritura del remate, abriendo las zanjas para los cimientos. ${ }^{25} \mathrm{El} 28$ de setiembre el gobierno decretó el aplazamiento de la demolición del antiguo hospital porque el nuevo aún no se había construido. ${ }^{25}$

Por entonces, el país entraba en una nueva crisis política, por primera vez era posible que un civil, Manuel Pardo, ganara las elecciones presidenciales de 1872. Balta llamó a su hermano Pedro, que dejó la prefectura en manos de Pedro José Bustamante y Alvizuri, quien la cedió a Juan Corrales Melgar. ${ }^{26}$ En julio de 1872, el presidente Balta era derrocado por Tomás Gutiérrez, su ministro de Guerra y Marina, y asesinado en prisión, El golpista fue a su vez muerto por la revuelta popular subsecuente, y Pardo fue exaltado a la presidencia de la República.

En la Guerra del Pacífico (1879-1883), Arequipa no se vería mayormente afectada, recién fue tomada incruentamente por los chilenos, el 29 de octubre de 1883, por lo que el hospital San Juan de Dios continuó funcionando. ${ }^{6}$ Entre 1882 y 1891 se asistieron a 41373 pacientes, de los cuales fallecieron 6190 (14,96\%), y la mortalidad se incrementó inusualmente en 1889 , cuando se presentaron epidemias de sarampión y viruela. ${ }^{6}$ En 1893, los gastos anuales ordinarios del hospital ascendían a 20800 soles. $^{6}$

En 1905, el cirujano norteamericano Nicholas Senn, quien hacía una gira por Sudamérica, narró una situación ruinosa del hospital San Juan de Dios: la asistencia de los enfermos era muy deficiente, no tenía médico residente ni internos, los enfermos que podían trabajar eran obligados a hacerlo y era demasiado pobre para dar una memoria anual impresa. ${ }^{27}$ En sus últimos años de existencia trabajaron los doctores Francisco Ángel Zegarra, cirujano que laboró hasta 1876, en que se trasladó a Lima; José Benedicto Montesinos Polar Garzón, abogado y cirujano que se entrenó en establecimientos de París y otras ciudades europeas, ocupando el rectorado de la universidad San Agustín, en 1882; Pedro José Ramírez Broussais, obstetra formado en Europa; Luciano Bedoya Zegarra, cirujano que laboró hasta la extinción del hospital en 1912; y, Benigno Ramírez del Villar, tocólogo formado en Alemania. ${ }^{28}$ 


\section{La familia Goyeneche y el nuevo hospital}

El 19 de febrero de 1872 fallecía José Sebastián de Goyeneche y Barreda, arzobispo de Lima y antiguo obispo de Arequipa. En la cláusula 14 de su testamento, abierto el 13 de marzo, estipuló que 150000 pesos se aplicarían a la construcción de un hospital en su ciudad natal. ${ }^{29}$

Cuando el 5 de abril de 1879 se inició la Guerra del Pacífico, el gobierno tomó todos los recursos económicos a la mano, entre ellos aquel legado.

Sólo a principios del siglo XX, el gobierno de Eduardo de López de Romaña (1899-1903), antiguo director de la SBA, $1889-1895$ y en 1897, reconoció la deuda del Estado, aunque hubo de recurrirse a la generosidad de los sobrinos del extinto arzobispo para plasmar el proyecto y, siendo todos ellos fervorosos católicos, seguramente consideraron un deber moral respetar la voluntad testamentaria de sus tíos Pedro Mariano, en $1845^{30}$ y José Sebastián, en $1872 . .^{29}$

El 1 de julio de 1905, se colocó la primera piedra en la chacra Calula, cedida por la SBA, en presencia del presidente José Pardo Barreda; y, los planos fueron trazados por los ingenieros franceses Gaillard y Ponsot, y adaptados por Pedro Paulet. ${ }^{31}$

El Congreso Nacional dio la resolución legislativa $\mathrm{N}^{\circ} 710$, el 25 de octubre de 1907, que ordenó que los materiales de construcción, muebles y demás artículos con destino al hospital que construía la familia Goyeneche en Arequipa, se despacharan libres de derechos fiscales por la aduana de Mollendo, hasta un monto de cinco mil libras peruanas. Desde 1909, cuando las obras se confiaron a los ingenieros Oscar López Aliaga y Julio Andrés Arce, hubo avances significativos. ${ }^{32}$ La mampostería, en que trabajaron doscientos operarios, se hizo bajo la dirección del ingeniero Manuel Cuba, y la construcción de los techos se encargó al arquitecto italiano José C. Vialardi, todo este proceso lo supervisó ad honorem José Antonio de Vivanco, que administraba, desde 1895, los intereses de los Goyeneche en Arequipa. ${ }^{33}$

La inauguración se señaló para el sábado 20 de enero de 1912, pero se postergó hasta el domingo 11 de febrero de 1912, en que se le bautizó Nuestra Señora del Consuelo, aunque desde antes se le denominó fácticamente hospital Goyeneche. ${ }^{33}$ Costó 125000 libras peruanas, y lo apadrinó Pio X, representado por Mariano Holguín, obispo de Arequipa, un aspecto que lo hace singular, junto a su arquitectura gótica. ${ }^{33}$

Los enfermos del antiguo nosocomio se trasladaron al Goyeneche, algunos de sus médicos pasaron a trabajar en el flamante establecimiento, como Luciano Bedoya Zegarra y Benigno Ramírez del Villar, ${ }^{34}$ y así quedó extinguido el hospital San Juan de Dios.

\section{COLOFÓN}

El existencia del hospital San Juan de Dios de Arequipa estuvo signada por los avatares de sus administradores y los gobiernos nacionales y, probablemente, de no mediar la iniciativa de la familia Goyeneche, única incluso para el Perú contemporáneo, hubiera subsistido muchos más años, pero, aquel proyecto embelesó a los arequipeños, quienes se deshicieron del doliente recuerdo que les suscitaba el antiguo nosocomio, tan relegado desde el primer día de su fundación, tal vez eso explica que hoy sea un recuerdo fantasmal para la gran mayoría de sus coterráneos a pesar de sus trescientos sesenta años de existencia.

\section{REFERENCIAS BIBLIOGRÁFICAS}

1. Cueto M. Excelencia científica en la periferia. Lima: Concytec; 1989. p.32,33.

2. Barrera H. Un acercamiento a la política asistencialista colonial. El caso del hospital Real de San Andrés, Revista del Archivo General de la Nación 2015;30:159-85.

3. Barriga V. Documentos para la historia de Arequipa 1534-1558, tomo 1. Arequipa: Editorial La Colmena; 1939. p.79,314,315, 319, 320, 323-325,362,363.

4. Lozada S. Apuntes para la historia médico-quirúrgica y hospitalaria de Arequipa. Arequipa: Establecimientos gráficos La Colmena; 1943. p.9.

5. Mendiburu M. Diccionario histórico biográfico del Perú, vol. 5. Lima: Imprenta Bolognesi; 1885. p.138.

6. Polar J. Arequipa. Descripción y estudio social. Arequipa: Tipografía Mercantil; 1891. p.181-3.

7. Recopilación de las leyes de los reynos de las Indias, tomo 1. Madrid: Imprenta de la viuda de Joaquín Ibarra; 1791. p.34.

8. Recopilación de las leyes de los reynos de las Indias, tomo 1. Madrid: Imprenta de Julián de Paredes; 1681. p.16.

9. Mendiburu M. Diccionario histórico biográfico del Perú, vol. 1. Lima: Imprenta J. Francisco Solís; 1874. p.171.

10. Cateriano M. Memorias de los ilustrísimos señores obispos de Arequipa. Arequipa: Tipografía Quiroz; 1908. p.161.

11. Zamacola J. Apuntes para la historia de Arequipa. Año de 1804. Arequipa: Imprenta de La Bolsa; 1888. p.48.

12. Unanue H. Guía política, eclesiástica y militar del virreynato del Perú para el año de 1793. Lima: Imprenta Real de los Huérfanos; 1792. p.264.

13. Unanue H. Guía política, eclesiástica y militar del virreynato del Perú para el año de 1795. Lima: Imprenta Real de los Niños Huérfanos; 1794. p. 210

14. Unanue H. Guía política, eclesiástica y militar del virreynato del Perú para el año de 1796. Lima: Imprenta Real de los Niños Huérfanos; 1795. p.239.

15. Unanue H. Guía política, eclesiástica y militar del virreynato del Perú para el año de 1797. Lima: Imprenta Real de los Niños Huérfanos; 1796. p.214.

16. Muñoz M. Liberalismo y bibliotecas. El proyecto de creación de una biblioteca pública en Valencia durante el Trienio Liberal. Revista General de Información y Documentación 2016; 26(1):555-81. doi: https://doi.org/10.5209/RGID.54715

17. Sala N. El Trienio Liberal en el Virreinato peruano: los ayuntamientos constitucionales de Arequipa, Cusco y Huamanga, 1820-1824. Revista de Indias. 2011;71(253):693-728. doi: https://doi.org/10.3989/ revindias.2011.023

18. Valdivia J. Manual para los bañantes en las aguas termales de Yura y de Jesús. Arequipa: Imprenta del Misti por Melchor Hinojosa; 1872. p. 46,47 .

19. Valdizán H. Crónicas Médicas. Lima: Talleres gráficos del Asilo Colonia Víctor Larco Herrera; 1929. p.65, 66, 72, 77.

20. Oviedo J. Colección de leyes, decretos y órdenes, 1821-1859. Lima: Librería Central; 1861. p.166.

21. Paz Soldán M. Geografía del Perú, tomo 1. París: Librería de Fermín Didot hermanos, hijos y Cía.; 1862. p.445.

22. Reglamento provisorio del Hospital San Juan de Dios. Arequipa: Imprenta de Francisco Ibáñez; 1868. p.2-4,8-17.

23. Boletín Oficial de leyes, decretos, resoluciones y oficios del gobierno. Segundo semestre de 1868. Lima: Imprenta del Estado; 1868. p.180,1 $82,272,299,304,305,338,339,430,431,450$.

24. Cabello P. Guía política, eclesiástica y militar del Perú para el año de 1869. Lima: Imprenta de la Guía; 1868. p.103. 
25. Boletín Oficial de leyes, decretos, resoluciones y oficios del gobierno. Segundo semestre de 1870. Lima: Imprenta del Estado; 1870. p.471,472, 546,548,558.

26. Mücke U. Estado nacional y poderes provinciales. Aspectos del sistema político peruano antes de la Guerra con Chile. Anuario de Estudios Americanos. 1999;56(1):173-94. doi: 10.3989/aeamer.1999. v56.i1.292

27. Seen N. La Medicina en el Perú. Notas de viaje en Sud América. La Crónica Médica. 1908;25(472):251-6.

28. Alayza F. Historia de la cirugía en el Perú. Lima: Editorial Monterrico S.A.; 1992. p.296,297.

29. Rada P. El arzobispo Goyeneche y apuntes para la historia del Perú. Roma: Imprenta Políglota Vaticana; 1917. p.681-683.

30. Malamud C. La consolidación de una familia de la oligarquía arequipeña: los Goyeneche. Quinto Centenario 1982;4:49-135.
31. Martínez S. Directores de la Beneficencia de esta ciudad de Arequipa. Arequipa: Tipografía Acosta; 1940. p.29.

32. Álvarez R. Apuntes para la historia de la patología clínica en el Perú 1850-1950. Lima: Editora Amarilys; 2004. p.135-137.

33. The Goyeneche Hospital, Arequipa. Perú to Day. 1911;3(12):34.

34. Rabí M. Diccionario histórico biográfico médico del Perú, 1ra edición. Lima: Larchgrafic SAC; 2007. p.100, 438.

\section{CORRESPONDENCIA:}

Ricardo Iván Álvarez-Carrasco

ralvarezcarrasco@yahoo.com

Fecha de recepción: 23-06-2020.

Fecha de aceptación: 03-08-2020.

Declaración de Conflicto de Intereses: Ninguno, según el autor.

Financiamiento: Por el autor. 